\title{
Association between Essential Tremor and Other Neurodegenerative Diseases: What Is the Epidemiological Evidence?
}

\author{
Hiral LaRoia ${ }^{\mathrm{a}}$ Elan D. Louis ${ }^{\mathrm{a}-\mathrm{d}}$ \\ ${ }^{a}$ Department of Neurology, ${ }^{b}$ GH Sergievsky Center, and 'Taub Institute for Research on Alzheimer's Disease and \\ the Aging Brain, College of Physicians and Surgeons, and ${ }^{\mathrm{d}}$ Department of Epidemiology, Mailman School of \\ Public Health, Columbia University, New York, N.Y., USA
}

\section{Key Words}

Essential tremor • Epidemiology • Parkinson's disease •

Alzheimer's disease $\cdot$ Dementia $\cdot$ Neurodegenerative condition

\begin{abstract}
Background: The possible links between essential tremor (ET) and Parkinson's disease (PD) and, more recently, between ET and Alzheimer's disease (AD) have been of great interest, particularly with the emergence of postmortem data suggesting that ET itself may be a neurodegenerative disease. Given the very high population prevalence of ET, its possible role as a risk factor for PD and AD is of special significance. At the center of this debate is the burgeoning evidence from epidemiological studies, examining whether there is an increased co-occurrence of these conditions within the same individuals or within families. Methods: We conducted a PubMed search from 1966 to March 2011 and reviewed the epidemiological evidence, restricting our analyses to studies that generated quantifiable measures of association (odds ratios or relative risks), thereby being able to assess the role of chance. Results: The most robust evi-
\end{abstract}

dence, from case-control, prospective and familial aggregation studies, indicates that ET is associated with increased odds and increased risks of both PD and AD. Conclusions: There is reasonable epidemiological evidence to support a link between ET and these neurodegenerative diseases. Further studies are needed to corroborate the current results, provide additional estimates of effect and begin to explore the mechanistic underpinnings for these intriguing associations.

Copyright $\odot 2011$ S. Karger AG, Basel

\section{Introduction}

Essential tremor (ET), whose core clinical feature is a progressive kinetic tremor of the arms, is one of the most common neurological diseases [1]. There are 28 population-based prevalence studies [2] and, based on these studies, it is clear that the crude prevalence $(0.4 \%$, all ages) rises markedly with age, reaching values of $6.3 \%$ among those $\geq 65$ years of age and $21.7 \%$ amongst those $\geq 95$ years [2]. Previously viewed as monosymptomatic and benign [3], ET has been increasingly recognized to be

\section{KARGER}

() 2011 S. Karger AG, Basel

Fax +41613061234 E-Mail karger@karger.ch www.karger.com www.karger.com/ned
Dr. Elan Louis

Unit 198, Neurological Institute

710 West 168 th Street

New York, NY 10032 (USA)

Tel. +1 212305 9194, E-Mail EDL2@ columbia.edu 
a syndrome characterized by a broader set of motor features (e.g. several types of tremor, gait abnormalities) as well as non-motor features [4-6].

Clinicians have long observed that there seems to be a tendency for ET patients to develop incident Parkinson's disease (PD), raising questions about a link between these two neurological diseases [7-12]. In addition, given the advanced age of many ET cases, the co-occurrence of Alzheimer's disease (AD) has been observed as well, and recent studies have suggested a greater co-occurrence of the two conditions than might be expected based on chance alone $[13,14]$. Along with these observations, recent evidence suggests that ET is a neurodegenerative condition [15-17], and investigators have sought to determine whether there are shared mechanisms underlying this group of disorders [12, 18].

Our aim in this review was to evaluate the epidemiological literature on the association between ET and other neurodegenerative conditions, focusing specifically on $\mathrm{PD}$ and $\mathrm{AD}$. To our knowledge, there has been no published review of the epidemiological evidence.

\section{Search Strategy and Selection Criteria}

References for this review were identified by searches of PubMed from 1966 until March 2011. The terms 'essential tremor', 'clinical', 'epidemiology', 'Parkinson's disease', 'cognition', 'dementia' and 'Alzheimer's disease' were crossed together in the search engine. Articles were also identified through searches of the authors' own files. We included all studies, which by generating quantifiable measures of association [i.e. odds ratios (ORs), relative risks (RRs) or hazards ratios (HRs)] were thereby able to assess the role of chance. We excluded the reports that studied 'tremor' non-specifically rather than the distinct disease entity ET. Only papers published in English were reviewed.

\section{Links between ET and PD}

\section{Introduction}

The possible link between ET and PD has been a subject of interest for some time. Dating back to the first comprehensive clinical review of ET in 1949 [19], there has been speculation regarding the possibility of a relationship between these two tremor disorders $[3,19,20]$, with clinicians observing that ET patients have a tendency over time to develop PD rather than the converse (i.e.
PD patients developing ET) $[8,9,11]$. The co-occurrence of the two disorders within the same families is also well documented [21]. Here, we review the studies that have examined the association between ET and PD. We limit our analyses to studies that produced quantifiable measures of association (i.e. OR, RR and HR) and, furthermore, excluded those reports that studied 'tremor' in a general manner rather than the specific disease condition ET $[7,8,10,21-28]$.

\section{Epidemiological Studies}

In 2007, a case-control study was conducted by Louis and Frucht [29] of outpatients at the Neurological Institute of New York. The authors reviewed electronic records of 210 patients who carried a diagnosis of PD and 210 patients who carried a diagnosis of Parkinson-plus syndrome, with the hypothesis that if some ET were an expression of Lewy body disease, one could hypothesize that ET patients who develop parkinsonism would be more likely to develop PD (i.e. a Lewy body disease) than a Parkinson-plus syndrome (i.e. a non-Lewy body form of parkinsonism). Patients with PD were more likely to have had a prior diagnosis of ET than patients with Parkinson-plus syndrome [7.1 vs. 2.4\%; OR $=3.16,95 \%$ confidence interval (CI) 1.13-8.85, p = 0.02] and more likely to have had a diagnosis of ET assigned by a neurologist at the Neurological Institute at the time of their visit (5.3 vs. $0.0 \%$; OR $=12.85,95 \%$ CI 1.66-99.80, $\mathrm{p}=0.001$ ) [29].

In 2008, a case-control study was conducted by Tan et al. [30] at a tertiary referral center in Singapore. The study groups included 204 outpatients with PD, 206 diseased controls (i.e. neurological outpatients with hemifacial spasm) and 190 healthy controls (medical and technical staff from the hospital as well as volunteers). Twelve (5.9\%) PD patients also carried a diagnosis of ET, compared to $2(1.7 \%)$ diseased controls $(\mathrm{OR}=6.4,95 \% \mathrm{CI}$ $1.5-27.7, \mathrm{p}=0.006)$ and $1(0.5 \%)$ healthy control $(\mathrm{OR}=$ $11.8,95 \%$ CI 1.9-71.3, $\mathrm{p}=0.003$ ) [30].

In 2010, a prospective, population-based study was conducted to estimate the incidence of PD in ET patients versus normal controls [31]. This study sample was comprised of 3,813 elderly persons (age $\geq 65$ years) residing in 3 communities in central Spain. The baseline evaluation consisted of an initial screening questionnaire followed by an in-person neurological examination; a follow-up examination was performed after a median time interval of 3.3 years. During that time interval, 12 of 207 (5.8\%) ET cases versus 56 of 3,606 (1.6\%) controls developed incident Parkinsonism (adjusted RR $=3.47,95 \%$ CI $1.82-6.59, \mathrm{p}<0.001)$. Furthermore, 6 of 201 (3.0\%) ET 
cases versus 24 of 3,574 (0.7\%) controls developed incident PD (adjusted RR $=4.27,95 \%$ CI 1.72-10.61, $\mathrm{p}=$ 0.002). The investigators estimated that the lifetime risk of developing PD was $8.5 \%$ in men with ET and $5.6 \%$ in women with $\mathrm{ET}$, compared to $2 \%$ in men and $1.3 \%$ in woman without ET [31].

While these studies each have their strengths and weaknesses, thoughtfully outlined in the individual papers, here, we will address those methodological aspects most likely to have affected the conclusions of the authors. The first issue is diagnostic misclassification and, in these studies, avoiding the mislabeling of PD as ET is a major challenge. Kinetic tremor, the central clinical feature of ET, is also a common feature of PD [32]; furthermore, isolated kinetic tremor may be the only clinical manifestation of early PD [33]. Hence, there is the theoretical possibility that individuals with $\mathrm{PD}$ are being mislabeled as ET. Consequently, the validity of the 'ET' diagnoses is an issue in each of these studies. Careful attention to clinical details (e.g. tremor characteristics), avoiding the lumping of all kinetic tremor into the ET category, sensitivity to physical examination finding red flags (e.g. the presence of postural tremor that involves pronation-supination rather than flexion-extension) and use of multiple neurologists to concur diagnosis are all methods that in general can be used to maximize validity. Neurophysiological methods may be used to help distinguish ET from other forms of tremor and some of these methods are portable. On the other hand, these additional tests add time to the study evaluation, which may be an issue in epidemiological field studies, and their diagnostic utility in those settings remains to be established. As pointed out by Benito-Leon et al. [31], the studies would have ideally conducted baseline imaging of the dopaminergic system to distinguish between the two diseases; however, this approach is not feasible in an epidemiological setting. Louis and Frucht [29] pointed out that this form of diagnostic misclassification, if present in their study, was likely to have affected both PD and Parkinson-plus syndrome patients equally and would not have affected their estimates of the OR. The same may be said of the study by Tan et al. [30]. Only the study conducted by Benito-Leon et al. [31] was prospectively performed, including a complete Unified Parkinson's Disease Rating scale motor examination [34] at baseline, in order to detect subtle or early clinical features of parkinsonism at baseline. Nevertheless, it is still conceivable that some of the 'ET' patients in that study had a forme fruste of PD at baseline, characterized by isolated kinetic tremor, rather than ET. To deal with this issue, the au- thors conducted a series of sensitivity analyses (e.g. exclusion of ET cases whose ET duration was briefest prior to the onset of incident PD, exclusion of study participants with any mild parkinsonian signs at baseline) [31]. In each of these sensitivity analyses, the RRs remained robust ( $\geq 3$ ), suggesting that this form of diagnostic misclassification could not have accounted for the results of that study [31].

Selection bias was a second potential limitation common to the three studies. Both Louis and Frucht [29] as well as Tan et al. [30] ascertained cases from tertiary referral centers, in New York and Singapore, perhaps accounting for a larger proportion of patients with dual diagnoses. Louis and Frucht [29] again pointed out that this tendency towards dual diagnosis would have applied equally to both study groups, and therefore, would not have influenced the estimate of the OR. Tan et al. [30] also attempted to address this issue by comparing the prevalence of ET in the PD group with that in a diseased control group (i.e. another group of neurological patients cared for at the same tertiary referral center); the ORs were similarly elevated in those comparisons, suggesting that the issue of dual diagnosis was not likely to have influenced the estimates of association. The study of Benito-Leon et al. [31], while population based, restricted enrollment to persons aged $\geq 65$ years, identifying an association in an older subgroup of ET cases. However, this does not raise concerns about bias but rather whether the results may be generalized to the broader population of all ET cases (i.e. all age groups).

A retrospective approach was utilized by Louis and Frucht [29] (i.e. clinical records of patients with PD and Parkinson-plus syndrome were reviewed in order to assess whether the patients had had prior diagnoses of ET). This raises the issue of reviewer bias (i.e. the reviewer may have had preconceived notions regarding the association between ET and PD). To address this issue, the authors highlighted that a second investigator, blinded to the study hypothesis, reviewed a sub-sample of 30 clinical records to assess independently whether a prior diagnosis of ET had been present or absent [29]. Agreement between the two neurologists was excellent (100\% concordance, $\kappa=1.0$ ) [29]. Further, they addressed the possibility that neurologists at the tertiary referral center, perhaps believing that a link exists between ET and PD, would have chosen to regard kinetic tremors in their PD patients as ET while chosen not to have done the same when confronted with kinetic tremor in patients with Parkinson-plus syndromes. They pointed out a number of reasons why this was not likely to have been the case, 
with the most compelling of these being that a larger proportion of PD patients than Parkinson-plus patients presented to the tertiary referral center with a pre-existing complaint of tremor and a diagnosis of ET (i.e. their diagnoses of ET preceded their initial evaluation at the tertiary referral center) [29]. Furthermore, in most, the ET diagnosis preceded their PD or Parkinson-plus syndrome diagnosis, indicating that the ET diagnosis was initially assigned without any bias related to the nature of the parkinsonian diagnosis [29].

After examining the best available data, these three epidemiological studies, including two case-control studies and one population-based prospective study, each provide measures of association that support the notion that there is a link between ET and PD and, furthermore, that the presence of baseline ET increases the risk of developing incident $\mathrm{PD}$ during follow-up. The magnitude of the increased odds/risk reported in these studies is on the order of 3-13. Presently, there are no contrary data, either from case-control or prospective studies, to refute the model that ET is a risk factor for PD.

\section{Genetic Epidemiological Studies}

Family studies are another valuable source of data. In 2007, investigators in the Mayo Clinic Family Study of Parkinson's Disease examined the risk of ET among relatives of patients with PD [35]. They compared 981 firstdegree relatives of 162 patients with incident PD from Olmstead County, Minn., USA, to 838 first-degree relatives of 147 controls (i.e. individuals who were free of tremor, PD or parkinsonism) from the same Olmsted county population. The first-degree relatives were first screened for tremor via telephone interview; those who screened positive were examined. For deceased or otherwise incapacitated relatives, the investigators contacted a proxy informant. In these population-based samples, the authors found that relatives of PD patients had a modest and marginally significantly increased risk of ET compared with relatives of controls ( $\mathrm{HR}=1.51,95 \%$ CI 0.95 $2.41, \mathrm{p}=0.08)$ and that the risk was highest among relatives of patients with younger onset of $\mathrm{PD}$ (i.e. $\leq 66$ years; $\mathrm{HR}=2.24,95 \%$ CI 1.26-3.98, $\mathrm{p}=0.006)$ [35]. Their data suggested that PD and ET may share familial susceptibility factors [35].

In 2009, a familial aggregation study was conducted through the PD Epidemiology Program Project of Crete [36]. The investigators evaluated a group of 303 patients with PD and a group of 249 controls, determining the extent to which ET was present in their respective firstdegree relatives. They also assessed the co-occurrence of
ET and PD within the same family and the co-occurrence of ET and PD in the same individual [36]. The investigators initially relied on proband reports; the diagnosis of ET was then confirmed by an in-person evaluation in $78 \%$ of the reportedly affected relatives of $\mathrm{PD}$ patients and in $70 \%$ of reportedly affected relatives of controls; for the remainder, the diagnoses were confirmed by medical record review and surrogate interviews. Twenty-six (8.6\%) of the PD patients reported at least one first-degree relative affected by ET, compared to 8 (3.2\%) control subjects $(\mathrm{OR}=2.83,95 \%$ CI 1.19-6.92, $\mathrm{p}=0.015)$ [36]. For PD, 41 of 1,483 (2.8\%) first-degree relatives had ET; for controls, 10 of 1,315 (0.8\%) first-degree relatives had ET $(\mathrm{OR}=3.64$, 95\% CI 1.75-7.77, $\mathrm{p}=0.0001$ ) [36]. Twelve individuals had both ET and PD. While this could have occurred due to chance, a number of families were identified in which ET and PD were co-inherited through the same parental line, suggesting that in certain families, ET and PD are genetically related, probably sharing a common hereditary predisposition [36].

A population-based family study, conducted by Costello et al. [37] in 2010 in rural California, evaluated the occurrence of ET (as well as AD) in the relatives of PD patients compared to controls. Three-hundred and seventy-two PD patients and 404 controls were recruited, and 2,980 first-degree relatives of PD cases and 2,981 first-degree relatives of control subjects were compared. The investigators used proband interviews to assess family history. Relatives of PD subjects were found to be at a modestly increased risk of having ET, though this increased risk only attained marginal statistical significance [37]. Thus, for the PD patients, 45 of 2,980 (1.5\%) first-degree relatives had ET; for controls, 31 of 2,981 (1.0\%) first-degree relatives had ET $(\mathrm{HR}=1.44,95 \% \mathrm{CI}$ $0.90-2.29, p=0.13$ ) [37]. In several subgroups, the risk of ET appeared to be most elevated: relatives of tremordominant PD cases $(\mathrm{HR}=1.69,95 \%$ CI $0.99-2.88, \mathrm{p}=$ $0.05)$, relatives of younger-onset $\mathrm{PD}$ cases $(\mathrm{HR}=2.03$, $95 \% \mathrm{CI} 0.93-4.44, \mathrm{p}=0.08)$ and male relatives $(\mathrm{HR}=2.31$, 95\% CI 1.13-4.73, $\mathrm{p}=0.02$ ) [37].

Among family studies, the method utilized to study relatives merits additional consideration. Ideally, investigators will conduct in-person examinations of all firstdegree relatives of PD cases and all first-degree relatives of controls in order to establish ET diagnoses. However, this is not generally feasible. In lieu of this, direct assessment of the relatives is preferable to the use of proband reports. One of the three studies directly assessed the relatives [35], while the two others [36,37] relied first or exclusively on proband reports. The issue one must con- 
sider is that of recall bias. Are relatives of PD cases more likely than controls to recall or report the presence of tremor in their relatives? In the study in Crete [36], approximately three quarters of the reportedly affected relatives were subsequently examined and the ET diagnosis was confirmed, but this does not address whether PD probands' reports may have been more sensitive than those of control probands. In the study at the Mayo Clinic [35], the relatives were assessed directly rather than through a proband, thereby by-passing this issue. Yet even in that study, the authors noted that the sensitivity of the telephone screen was $84.6 \%$ in relatives of cases and $60.0 \%$ in relatives of controls, raising the question as to whether relatives of cases are better able to provide valid reports of their tremor status than relatives of controls.

After examining the best available data, these three genetic epidemiological studies each support the notion that there is an association between ET and PD, and there are no studies to the contrary. Additional studies, which rely on direct neurological examination of relatives, are needed in order to more fully address the concerns raised about recall bias and validity of relatives' reports. Furthermore, studies examining the risk of PD in relatives of ET cases versus relatives of controls have yet to be undertaken.

\section{Biological Evidence}

There are findings that support, from a biological perspective, the notion of an association between ET and PD. For example, although a number of imaging studies have indicated clear differences between ET and PD in terms of the underlying biological substrate in the basal ganglia $[38,39]$, other studies have suggested that there may be some degree of overlap. For example, a series of papers using SPECT imaging demonstrated that ET patients had mild abnormalities of striatal dopamine transporters and a significant presynaptic dopaminergic deficit [40, 41]. Others have demonstrated that ET patients who develop isolated rest tremor have evidence on neuroimaging studies of mild nigral neuronal loss [42] and that there is evidence of reduced striatal volume in ET as well [43]. Therefore, the literature is somewhat mixed, with the central question being whether changes in the basal ganglia are a feature of a subgroup of patients who have bone fide ET or whether the 'ET' patients with these imaging abnormalities have a forme fruste of PD rather than ET. Given the number of studies that suggest an overlap, there seems to be some biological support for a link between ET and PD. These findings are then further supported by genetic studies, which demonstrate that some of the same genet- ic variants are associated with both ET and PD [44]. More recently, some postmortem studies have demonstrated the presence of more brainstem Lewy bodies in ET cases than in similarly aged controls, suggesting the presence of a Lewy body variant of ET and raising the possibility that these cases might be at increased risk of developing a more complete Lewy body syndrome (i.e. PD) [16].

\section{Summary}

The aggregated epidemiological data, from three independent studies, support the notion that there is an association between ET and PD. The magnitude of the increased odds/risk reported in the three epidemiological studies is on the order of 3-13. Moreover, from three genetic epidemiological studies, there is evidence that ET and PD seem to co-occur in families to an extent greater than expected by chance alone, with PD patients being more likely than controls to have first-degree relatives with ET. These epidemiological and genetic epidemiological data are consistent with biological evidence, which further supports the possibility of common disease mechanisms and pathogenesis.

\section{Links between ET and AD}

\section{Introduction}

Numerous studies have reported on the prevalence of extrapyramidal signs in AD patients [45-49], with reports of the prevalence of rest tremor ranging from 4 to $20 \%[50,51]$. With regard to tremors aside from rest tremor (i.e. action tremor), some studies point to a higher prevalence in $\mathrm{AD}$ patients than in controls [48, 52]; thus, in one study, $48.5 \%$ of neuroleptic-free $\mathrm{AD}$ cases versus $32.8 \%$ of controls had other (non-rest) tremors [48], and action tremor scores were significantly higher in AD cases than in controls in another study [52]. Conversely, the presence of cognitive dysfunction is an increasingly recognized feature of ET, with these cognitive deficits primarily in the domains of executive function and memory, and a number of these studies have involved case-control comparisons (i.e. demonstrating greater cognitive impairment in ET cases than in similarly aged controls) [53-61]. Recent epidemiological literature has also documented an increased odds of mild cognitive impairment (MCI) among older-onset ET cases than among controls [62] and, as will be reviewed below, several epidemiological studies have emerged, documenting associations between ET and dementia (specifically AD). 


\section{Epidemiological Evidence}

A series of papers from the Neurological Disorders in Central Spain (NEDICES) study, a population-based study in central Spain, examined the associations between ET and cognitive dysfunction [54, 61], prevalent MCI [62] and both prevalent and incident dementia [14, 58]. ET cases were all ascertained from three communities in central Spain and were aged $\geq 65$ years. The investigators demonstrated that these ET cases performed less well than controls on neuropsychological and cognitive testing, particularly on tests of memory and frontal executive testing, and that they had increased subjective forgetfulness $[54,61]$. These study subjects were then followed longitudinally, and the rate of cognitive decline appeared to be faster in ET cases than in controls; thus, at baseline, the scores on a 37-item version of the mini-mental state examination were $28.8 \pm 5.8$ in ET cases versus $30.2 \pm 4.8$ in controls $(\mathrm{p}=0.02)$. During the 3 -year follow-up period, the 37 -item version of the mini-mental state examination declined by $0.70 \pm 3.2$ points in cases versus $0.11 \pm 3.8$ points in controls $(\mathrm{p}=0.03)$ [61].

In that same study, the investigators established links between prevalent ET and prevalent MCI [62]. Thus, 42 (20.3\%) of 207 ET cases had MCI versus 399 (16.1\%) of 2,472 controls $(\mathrm{OR}=1.32,95 \%$ CI $0.93-1.89, \mathrm{p}=0.12)$. In an adjusted model $(\mathrm{OR}=1.28,95 \%$ CI $0.88-1.84, \mathrm{p}=$ 0.19 ), ET cases with tremor onset after age 65 years were $57 \%$ more likely to have MCI than controls (adjusted $\mathrm{OR}=1.57,95 \% \mathrm{CI} 1.03-2.38, \mathrm{p}=0.03$ ), whereas ET cases with tremor onset prior to age 65 years and controls were equally likely to have MCI (adjusted OR $=0.73,95 \% \mathrm{CI}$ $0.34-1.57, \mathrm{p}=0.43$ ).

The NEDICES study was also used to examine the associations between ET and more severe forms of cognitive impairment (i.e. dementia). Thus, the prevalence of dementia at baseline was increased in ET patients with older age of onset. Thirty-one of 273 (11.4\%) ET cases with onset after age 65 years versus 204 of 3,382 (6\%) controls had dementia at baseline (adjusted OR $=1.70,95 \%$ CI $1.04-2.76, \mathrm{p}=0.03$ ) [58]. The NEDICES cohort was followed over time. During the mean duration of followup of 3.2 years, 16 (7.8\%) of 206 ET cases developed incident dementia versus 145 (3.9\%) of 3,685 controls (adjusted $\mathrm{RR}=1.66,95 \%$ CI $0.99-2.80, \mathrm{p}=0.054)$. In an adjusted model, ET cases with tremor onset after age 65 years were twice as likely to develop incident dementia than were controls $(\mathrm{RR}=1.98,95 \%$ CI 1.14-3.45, $\mathrm{p}=0.01)$ [14].

A second prospective, population-based study of elders (age $\geq 65$ years) was conducted in northern Manhattan, New York [13]. In cross-sectional analyses, 31 of 124
(25.0\%) ET cases had prevalent dementia versus 198 of 2,161 (9.2\%) controls (adjusted OR $=1.84,95 \%$ CI 1.13$2.98, \mathrm{p}=0.01)$. In prospective analyses, 17 of $93(18.3 \%)$ ET cases versus 171 of $1,963(8.7 \%)$ controls developed incident dementia (adjusted HR $=1.64,95 \%$ CI 0.99-2.72, $\mathrm{p}=0.055)$. Thus, in a second population-based study of elders, ET was associated with both increased odds of prevalent dementia and increased risk of incident dementia.

The two current studies $[13,14]$ are limited in the sense that all enrolled ET cases were aged $\geq 65$ years; nevertheless, this is precisely the age group with the highest prior probability of developing dementia, and hence, it is of the greatest interest. Whether some of the ET cases in these studies had PD rather than ET is a question which one must ask. In the Spanish study, the authors conducted the motor portion of the Unified Parkinson's Disease Rating scale both at baseline and at follow-up in order to limit this possibility [14]. The other potential limitation of these studies is that the evaluation of depression, a potential confounder because it is associated both with ET and with dementia, was limited $[13,14]$.

\section{Biological Evidence}

The biological basis for the cognitive dysfunction and dementia associated with ET is unclear, although a number of mechanisms may be operative. Furthermore, the basis for the cognitive dysfunction is very possibly distinct from that of the dementia. In terms of the former, one must consider the involvement of the cerebellum and its outflow pathways [53]. There is a longstanding clinical literature that converges on the notion that $\mathrm{ET}$ is a disorder of cerebellar dysregulation, including the presence in ET patients of intention tremor $[63,64]$, gait ataxia $[65$, 66], oculomotor abnormalities [67] and problems with dysrhythmia and motor learning [68-73]. Deep brain stimulation surgery in ET targets the specific thalamic nucleus (i.e. ventral intermediate) that is the cerebellar receiving area, providing further support for this notion. A variety of neuroimaging studies, including functional MRI [74], positron emission tomography [75-77], ${ }^{1} \mathrm{H}$ magnetic resonance spectroscopic imaging $[78,79]$, diffusion tensor imaging [80-82], voxel-based morphometry $[83,84]$ and studies using other automated volumetric methods [85], now indicate the presence not only of functional and metabolic abnormalities in the ET cerebellum, but of both gray and white matter structural abnormalities as well. Although other brain regions (especially red nucleus) variably show abnormalities in select imaging studies $[76,80,83]$, it is the cerebellum that is consistent- 
ly implicated in these numerous imaging studies. More recently, postmortem studies in ET have indicated the presence of a variety of structural and degenerative changes in the cerebellum, including increased number of Purkinje cell axonal swellings ('torpedoes'), increased number of displaced or heterotopic Purkinje cells, reduction in number of Purkinje cells, and hypertrophy of basket cell processes ('hairy baskets') [16, 86, 87]. Although the cerebellum was originally thought to be purely a mediator of motor function and coordination, some have suggested that the cerebellum participates in facilitating psychological and learning activities [55, 88-92]. These findings have given rise to the theory of an abnormality in a cerebellothalamocortical or cerebellothalamofrontal network in ET patients with cognitive deficits [53, 59, 93].

One must also consider the ET cases who go on to develop frank dementia [14]. In both the New York [13] and Spanish studies $[14,58]$, the large majority of ET cases who developed incident dementia carried clinical diagnoses of $\mathrm{AD}$ rather than other types of dementia, making this the most likely pathogenesis. The postmortem studies also suggest that there may be an increase in Alzheimer-type changes in the ET brain (i.e. neurofibrillary tangles and neuritic plaques) [94], providing further support for this notion.

\section{Summary}

Studies have demonstrated that some patients with ET clearly have evidence of cognitive dysfunction, primarily in executive function. It has been hypothesized that this is mediated through cerebellar, thalamic and frontal connections. Yet aside from this, there is an emerging epidemiological literature that is beginning to point to an association between ET cases of older age and frank dementia, with most of the cases carrying clinical diagnoses of $\mathrm{AD}$ and postmortem work beginning to provide some support for this notion. The increase in risk of $\mathrm{AD}$ in these ET cases is modest (i.e. on the order of 1.6- to 2-fold) in studies in Spain and New York.

\section{Conclusions Regarding Links between ET and Other Neurodegenerative Diseases}

ET, a distinct neurological disease, is no longer considered to be a single neurological sign (action tremor) [4, 15]. Rather, it is now recognized to be a clinically more complex disorder with both motor and non-motor features $[4,15]$. ET itself shares a number of important features with neurodegenerative conditions. These include its association with advancing age, its insidious onset, its progressive clinical course, as well as the presence of neuronal loss on postmortem examination. Hence, it is likely that ET itself is neurodegenerative $[15,17,95]$. There is a sizable literature demonstrating that neurodegenerative diseases may be associated with one another, with the notion being that the development of one such disorder is a marker of a biological propensity/vulnerability for the development of others. Hence, the co-occurrence of amyotrophic lateral sclerosis with frontotemporal dementia within individuals and within families is well documented [96-98], and it is well established that a high proportion of PD patients with dementia have concurrent $\mathrm{AD}$ [99]. We are unaware of prior studies that have focused specifically on an evaluation of the epidemiological data with respect to ET and its associations with $\mathrm{AD}$ and PD. Epidemiological studies, which have now begun to emerge over the past 5 years, suggest a commonality of ET with PD and AD. More specifically, our review of the current epidemiological data indicates that there is growing evidence to support a link between ET and PD. Although the number of studies examining the epidemiological links between ET and AD are modest, these studies are also pointing towards an association between these two diseases.

To further assess the links between these diseases, additional epidemiological (i.e. case-control as well as prospective) studies and additional family studies with direct neurological examination of relatives are needed. Furthermore, continued examination of postmortem brain tissue and genetic susceptibility data will also aid in the evaluation of links between these diseases. With these added data, one can expand the current results, provide additional estimates of effect and begin to explore the mechanistic underpinnings for these intriguing associations.

\section{Acknowledgements and Funding}

We wish to acknowledge funding from R01 NS42859 and R01 NS039422 from the National Institutes of Health (Bethesda, Md., USA) and the Parkinson's Disease Foundation.

\section{Disclosure Statement}

The authors report no conflicts of interest. 


\section{References}

1 Benito-Leon J: How common is essential tremor? Neuroepidemiology 2009;32:215216

2 Louis ED, Ferreira JJ: How common is the most common adult movement disorder? Update on the worldwide prevalence of essential tremor. Mov Disord 2010;25:534 541.

>3 Hornabrook RW, Nagurney JT: Essential tremor in Papua, New Guinea. Brain 1976; 99:659-672.

$\checkmark 4$ Benito-Leon J: Essential tremor: from a monosymptomatic disorder to a more complex entity. Neuroepidemiology 2008;31: 191-192.

5 Louis ED: Essential tremor as a neuropsychiatric disorder. J Neurol Sci 2010;289:144148.

6 Louis ED: Factor analysis of motor and nonmotor signs in essential tremor: are these signs all part of the same underlying pathogenic process? Neuroepidemiology 2009;33: 41-46.

7 Geraghty JJ: Association between essential tremor and Parkinson's disease. Ann Neurol 1985; 17:329-333.

8 Lou JS, Jankovic J: Essential tremor: clinical correlates in 350 patients. Neurology 1991; 41:234-238

-9 Chaudhuri KR, Buxton-Thomas M, Dhawan V, Peng R, Meilak C, Brooks DJ: Long duration asymmetrical postural tremor is likely to predict development of Parkinson's disease and not essential tremor: clinical follow up study of 13 cases. J Neurol Neurosurg Psychiatry 2005;76:115-117.

$>10$ Koller WC, Busenbark K, Miner K: The relationship of essential tremor to other movement disorders: report on 678 patients. Essential Tremor Study Group. Ann Neurol 1994;35:717-723.

-11 Minen MT, Louis ED: Emergence of Parkinson's disease in essential tremor: a study of the clinical correlates in 53 patients. Mov Disord 2008;23:1602-1605.

$\checkmark 12$ Bermejo PE, Ruiz-Huete C, Terron C: Relationship between essential tremor, Parkinson's disease and dementia with Lewy bodies. Rev Neurol 2007;45:689-694.

13 Thawani SP, Schupf N, Louis ED: Essential tremor is associated with dementia: prospective population-based study in New York. Neurology 2009;73:621-625.

-14 Bermejo-Pareja F, Louis ED, Benito-Leon J: Risk of incident dementia in essential tremor: a population-based study. Mov Disord 2007;22:1573-1580.

15 Benito-Leon J: Essential tremor: one of the most common neurodegenerative diseases? Neuroepidemiology 2011;36:77-78.

$\checkmark 16$ Louis ED: Essential tremor: evolving clinicopathological concepts in an era of intensive post-mortem enquiry. Lancet Neurol 2010;9: 613-622.
17 Bermejo-Pareja F, Benito-Leon J: Essential tremor is a neurodegenerative disease. Med Clin (Barc) 2010;135:626-627, author reply 627.

18 Louis ED: Essential tremor. Lancet Neurol 2005;4:100-110

19 Critchley M: Observations on essential (heredofamial) tremor. Brain 1949;72:113139.

20 Barbeau A, Pourcher E: New data on the genetics of Parkinson's disease. Can J Neurol Sci 1982;9:53-60.

21 Yahr MD, Orosz D, Purohit DP: Co-occurrence of essential tremor and Parkinson's disease: clinical study of a large kindred with autopsy findings. Parkinsonism Relat Disord 2003;9:225-231.

22 Louis ED, Levy G, Mejia-Santana H, Cote L, Andrews H, Harris J, Waters C, Ford B, Frucht S, Fahn S, Ottman R, Marder K: Risk of action tremor in relatives of tremor-dominant and postural instability gait disorder PD. Neurology 2003;61:931-936.

23 Jankovic J, Beach J, Schwartz K, Contant C: Tremor and longevity in relatives of patients with Parkinson's disease, essential tremor and control subjects. Neurology 1995;45: 645-648.

24 Lang AE, Kierans C, Blair RD: Family history of tremor in Parkinson's disease compared with those of controls and patients with idiopathic dystonia. Adv Neurol 1987; 45:313-316.

25 Cleeves L, Findley LJ, Koller W: Lack of as sociation between essential tremor and Parkinson's disease. Ann Neurol 1988;24:23-26.

26 Marttila RJ, Rinne UK: Parkinson's disease and essential tremor in families of patients with early-onset Parkinson's disease. J Neurol Neurosurg Psychiatry 1988;51:429-431.

27 Marttila RJ, Rautakorpi I, Rinne UK: The relation of essential tremor to Parkinson's disease. J Neurol Neurosurg Psychiatry 1984;47: 734-735.

28 Lang AE: Association between familial tremor and Parkinson's disease. Ann Neurol 1986;19:306-307.

29 Louis ED, Frucht SJ: Prevalence of essential tremor in patients with Parkinson's disease vs Parkinson-plus syndromes. Mov Disord 2007;22:1402-1407.

30 Tan EK, Lee SS, Fook-Chong S, Lum SY: Evidence of increased odds of essential tremor in Parkinson's disease. Mov Disord 2008;23: 993-997.

-31 Benito-Leon J, Louis ED, Bermejo-Pareja F: Risk of incident Parkinson's disease and parkinsonism in essential tremor: a population based study. J Neurol Neurosurg Psychiatry 2009;80:423-425

32 Louis ED, Levy G, Cote LJ, Mejia H, Fahn S, Marder K: Clinical correlates of action tremor in Parkinson disease. Arch Neurol 2001; 58:1630-1634.
33 Jain S, Lo SE, Louis ED: Common misdiagnosis of a common neurological disorder: how are we misdiagnosing essential tremor? Arch Neurol 2006;63:1100-1104.

>34 Richards M, Marder K, Cote L, Mayeux R: Interrater reliability of the Unified Parkinson's Disease Rating Scale motor examination. Mov Disord 1994;9:89-91.

>35 Rocca WA, Bower JH, Ahlskog JE, Elbaz A, Grossardt BR, McDonnell SK, Schaid DJ, Maraganore DM: Increased risk of essential tremor in first-degree relatives of patients with Parkinson's disease. Mov Disord 2007; 22:1607-1614.

36 Spanaki C, Plaitakis A: Essential tremor in Parkinson's disease kindreds from a population of similar genetic background. Mov Disord 2009;24:1662-1668.

37 Costello S, Bordelon Y, Bronstein J, Ritz B: Familial associations of Alzheimer disease and essential tremor with Parkinson disease. Eur J Neurol 2010;17:871-878.

$\checkmark 38$ Asenbaum S, Pirker W, Angelberger P, Bencsits G, Pruckmayer M, Brucke T: $\left.{ }^{123} \mathrm{I}\right]$ betaCIT and SPECT in essential tremor and Parkinson's disease. J Neural Transm 1998;105: 1213-1228.

-39 Benamer TS, Patterson J, Grosset DG, Booij J, de Bruin K, van Royen E, Speelman JD, Horstink MH, Sips HJ, Dierckx RA, Versijpt J, Decoo D, Van Der Linden C, Hadley DM, Doder M, Lees AJ, Costa DC, Gacinovic S, Oertel WH, Pogarell O, Hoeffken H, Joseph K, Tatsch K, Schwarz J, Ries V: Accurate differentiation of parkinsonism and essential tremor using visual assessment of $\left[{ }^{123} \mathrm{I}\right]-\mathrm{FP}$ CIT SPECT imaging: the $\left[{ }^{123} \mathrm{I}\right]-\mathrm{FP}-\mathrm{CIT}$ Study Group. Mov Disord 2000;15:503-510.

40 Isaias IU, Canesi M, Benti R, Gerundini P, Cilia R, Pezzoli G, Antonini A: Striatal dopamine transporter abnormalities in patients with essential tremor. Nucl Med Commun 2008;29:349-353.

41 Antonini A, Isaias IU: Imaging evidence supports a link between essential tremor and Parkinson's disease. Nucl Med Commun 2009;30:93-94.

-42 Lee MS, Kim YD, Im JH, Kim HJ, Rinne JO, Bhatia KP: ${ }^{123} \mathrm{I}-\mathrm{IPT}$ brain SPECT study in essential tremor and Parkinson's disease. Neurology 1999;52:1422-1426.

43 Schwartz M, Groshar D, Inzelberg R, Hocherman S: Dopamine-transporter imaging and visuo-motor testing in essential tremor, practical possibilities for detection of early stage Parkinson's disease. Parkinsonism Relat Disord 2004;10:385-389.

44 Vilarino-Guell C, Wider C, Ross OA, Jasinska-Myga B, Kachergus J, Cobb SA, Soto-Ortolaza AI, Behrouz B, Heckman MG, Diehl NN, Testa CM, Wszolek ZK, Uitti RJ, Jankovic J, Louis ED, Clark LN, Rajput A, Farrer MJ: LINGO1 and LINGO2 variants are associated with essential tremor and Parkinson disease. Neurogenetics 2010;11:401-408. 
45 Mitchell SL: Extrapyramidal features in Alzheimer's disease. Age Ageing 1999;28: 401-409.

46 Capitani E, Francescani A, Spinnler H: Are hallucinations and extrapyramidal signs associated with a steeper cognitive decline in degenerative dementia patients? Neurol Sci 2007:28:245-250.

-47 Burns JM, Galvin JE, Roe CM, Morris JC, McKeel DW: The pathology of the substantia nigra in Alzheimer disease with extrapyramidal signs. Neurology 2005;64:1397-1403.

48 Tsolaki M, Kokarida K, Iakovidou V, Stilopoulos E, Meimaris J, Kazis A: Extrapyramidal symptoms and signs in Alzheimer's disease: prevalence and correlation with the first symptom. Am J Alzheimers Dis Other Demen 2001;16:268-278.

-49 Caligiuri MP, Peavy G, Galasko DR: Extrapyramidal signs and cognitive abilities in Alzheimer's disease. Int J Geriatr Psychiatry 2001;16:907-911.

-50 Scarmeas N, Hadjigeorgiou GM, Papadimitriou A, Dubois B, Sarazin M, Brandt J, Albert M, Marder K, Bell K, Honig LS, Wegesin D, Stern Y: Motor signs during the course of Alzheimer disease. Neurology 2004;63:975982.

-51 Samson WN, van Duijn CM, Hop WC, Hofman A: Clinical features and mortality in patients with early-onset Alzheimer's disease. Eur Neurol 1996;36:103-106.

-52 Gnanalingham KK, Byrne EJ, Thornton A, Sambrook MA, Bannister P: Motor and cognitive function in Lewy body dementia: comparison with Alzheimer's and Parkinson's diseases. J Neurol Neurosurg Psychiatry 1997;62:243-252.

- 53 Troster AI, Woods SP, Fields JA, Lyons KE, Pahwa R, Higginson CI, Koller WC: Neuropsychological deficits in essential tremor: an expression of cerebello-thalamo-cortical pathophysiology? Eur J Neurol 2002;9:143151.

54 Benito-Leon J, Louis ED, Bermejo-Pareja F: Population-based case-control study of cognitive function in essential tremor. Neurology 2006;66:69-74.

-55 Lombardi WJ, Woolston DJ, Roberts JW, Gross RE: Cognitive deficits in patients with essential tremor. Neurology 2001;57:785790.

56 Lacritz LH, Dewey R Jr, Giller C, Cullum $\mathrm{CM}$ : Cognitive functioning in individuals with 'benign' essential tremor. J Int Neuropsychol Soc 2002;8:125-129.

-57 Duane DD, Vermilion KJ: Cognitive deficits in patients with essential tremor. Neurology 2002;58:1706, author reply 1706

- 58 Benito-Leon J, Louis ED, Bermejo-Pareja F: Elderly-onset essential tremor is associated with dementia. Neurology 2006;66:15001505.
59 Sahin HA, Terzi M, Ucak S, Yapici O, Basoglu T, Onar M: Frontal functions in young patients with essential tremor: a case comparison study. J Neuropsychiatry Clin Neurosci 2006;18:64-72.

60 Gasparini M, Bonifati V, Fabrizio E, Fabbrini G, Brusa L, Lenzi GL, Meco G: Frontal lobe dysfunction in essential tremor: a preliminary study. J Neurol 2001;248:399-402.

61 Louis ED, Benito-Leon J, Vega-Quiroga S, Bermejo-Pareja F: Faster rate of cognitive decline in essential tremor cases than controls: a prospective study. Eur J Neurol 2010;17: 1291-1297.

62 Benito-Leon J, Louis ED, Mitchell AJ, Bermejo-Pareja F: Elderly-onset essential tremor and mild cognitive impairment: a population-based study (NEDICES). J Alzheimers Dis 2011;23:727-735.

63 Leegwater-Kim J, Louis ED, Pullman SL, Floyd AG, Borden S, Moskowitz CB, Honig LS: Intention tremor of the head in patients with essential tremor. Mov Disord 2006;21: 2001-2005.

64 Louis ED, Frucht SJ, Rios E: Intention tremor in essential tremor: prevalence and association with disease duration. Mov Disord 2009;24:626-627.

65 Singer C, Sanchez-Ramos J, Weiner WJ: Gait abnormality in essential tremor. Mov Disord 1994;9:193-196.

-66 Stolze H, Petersen G, Raethjen J, Wenzelburger R, Deuschl G: The gait disorder of advanced essential tremor. Brain 2001;124 2278-2286.

67 Helmchen C, Hagenow A, Miesner J, Sprenger A, Rambold H, Wenzelburger R, Heide W, Deuschl G: Eye movement abnormalities in essential tremor may indicate cerebellar dysfunction. Brain 2003;126:13191332.

68 Trillenberg P, Fuhrer J, Sprenger A, Hagenow A, Kompf D, Wenzelburger R, Deuschl G, Heide W, Helmchen C: Eye-hand coordination in essential tremor. Mov Disord 2006; 21:373-379.

69 Avanzino L, Bove M, Tacchino A, Ruggeri P, Giannini A, Trompetto C, Abbruzzese G: Cerebellar involvement in timing accuracy of rhythmic finger movements in essential tremor. Eur J Neurosci 2009;30:1971-1979.

70 Bares M, Lungu OV, Husarova I, Gescheidt T: Predictive motor timing performance dissociates between early diseases of the cerebellum and Parkinson's disease. Cerebellum 2010;9:124-135.

71 Farkas Z, Szirmai I, Kamondi A: Impaired rhythm generation in essential tremor. Mov Disord 2006;21:1196-1199.

72 Shill HA, De La Vega FJ, Samanta J, Stacy M: Motor learning in essential tremor. Mov Disord 2009;24:926-928.

-73 Kronenbuerger M, Gerwig M, Brol B, Block F, Timmann D: Eyeblink conditioning is impaired in subjects with essential tremor. Brain 2007;130:1538-1551.
74 Bucher SF, Seelos KC, Dodel RC, Reiser M, Oertel WH: Activation mapping in essential tremor with functional magnetic resonance imaging. Ann Neurol 1997;41:32-40.

75 Jenkins I, Bain P, Colebatch J, Thompson P, Findley L, Frackowiak S, Marsden C, Brooks D: A positron emission tomography study of essential tremor: evidence for overactivity of cerebellar connections. Ann Neurol 1993;34: 82-90.

76 Wills AJ, Jenkins IH, Thompson PD, Findley LJ, Brooks DJ: Red nuclear and cerebellar but no olivary activation associated with essential tremor: a positron emission tomographic study. Ann Neurol 1994;36:636-642.

-77 Colebatch JG, Findley LJ, Frackowiak RS, Marsden CD, Brooks DJ: Preliminary report: activation of the cerebellum in essential tremor. Lancet 1990;336:1028-1030.

78 Louis ED, Shungu DC, Chan S, Mao X, Jurewicz EC, Watner D: Metabolic abnormality in the cerebellum in patients with essential tremor: a proton magnetic resonance spectroscopic imaging study. Neurosci Lett 2002; 333:17-20.

79 Pagan FL, Butman JA, Dambrosia JM, Hallett M: Evaluation of essential tremor with multi-voxel magnetic resonance spectroscopy. Neurology 2003;60:1344-1347.

80 Shin DH, Han BS, Kim HS, Lee PH: Diffusion tensor imaging in patients with essential tremor. AJNR Am J Neuroradiol 2008; 29:151-153.

81 Klein JC, Lorenz B, Kang JS, Baudrexel S, Seifried C, van de Loo S, Steinmetz H, Deichmann R, Hilker R: Diffusion tensor imaging of white matter involvement in essential tremor. Hum Brain Mapp 2010, Epub ahead of print

82 Nicoletti G, Manners D, Novellino F, Condino F, Malucelli E, Barbiroli B, Tonon C, Arabia G, Salsone M, Giofre L, Testa C, Lanza P, Lodi R, Quattrone A: Diffusion tensor MRI changes in cerebellar structures of patients with familial essential tremor. Neurology 2010;74:988-994.

83 Benito-Leon J, Alvarez-Linera J, HernandezTamames JA, Alonso-Navarro H, JimenezJimenez FJ, Louis ED: Brain structural changes in essential tremor: voxel-based morphometry at 3-Tesla. J Neurol Sci 2009; 287:138-142.

84 Quattrone A, Cerasa A, Messina D, Nicoletti G, Hagberg GE, Lemieux L, Novellino F, Lanza P, Arabia G, Salsone M: Essential head tremor is associated with cerebellar vermis atrophy: a volumetric and voxel-based morphometry MR imaging study. AJNR Am J Neuroradiol 2008;29:1692-1697.

85 Cerasa A, Messina D, Nicoletti G, Novellino F, Lanza P, Condino F, Arabia G, Salsone M, Quattrone A: Cerebellar atrophy in essential tremor using an automated segmentation method. AJNR Am J Neuroradiol 2009;30: $1240-1243$ 
86 Kuo SH, Erickson-Davis C, Gillman A, Faust PL, Vonsattel JP, Louis ED: Increased number of heterotopic Purkinje cells in essential tremor. J Neurol Neurosurg Psychiatry 2010, Epub ahead of print.

-87 Erickson-Davis CR, Faust PL, Vonsattel JP, Gupta S, Honig LS, Louis ED: 'Hairy baskets' associated with degenerative Purkinje cell changes in essential tremor. J Neuropathol Exp Neurol 2010;69:262-271.

-88 Middleton F, Strick P: Basal ganglia and cerebellar loops: motor and cognitive circuits. Brain Res Rev 2000;31:236-250.

89 Rapoport M, van Reekum R, Mayberg H: The role of the cerebellum in cognition and behavior: a selective review. J Neuropsychiatry Clin Neurosci 2000;12:193-198.

-90 Schmahmann J: Disorders of the cerebellum: ataxia, dysmetria of thought, and the cerebellar cognitive affective syndrome. J Neuropsychiatry Clin Neurosci 2004;16:367-378.
91 Schmahmann J, Sherman J: The cerebellar cognitive affective syndrome. Brain 1998; 121:561-579.

92 Watson P: Nonmotor functions of the cerebellum. Psychol Bull 1978;85:944-967.

93 Kim JS, Song IU, Shim YS, Park JW, Yoo JY, Kim YI, Lee KS: Cognitive impairment in essential tremor without dementia. J Clin Neurol 2009; 5:81-84.

$\$ 94$ Louis ED, Faust PL, Vonsattel JP, Honig LS, Rajput A, Robinson CA, Pahwa R, Lyons KE, Ross GW, Borden S, Moskowitz CB, Lawton A, Hernandez N: Neuropathological changes in essential tremor: 33 cases compared with 21 controls. Brain 2007;130:3297-3307.

95 Louis ED, Benito-Leon J, Bermejo-Pareja F Antihypertensive agents and risk of Parkinson's disease, essential tremor and dementia: a population-based prospective study (NEDICES). Neuroepidemiology 2009;33: 286-292.
96 Giordana MT, Ferrero P, Grifoni S, Pellerino A, Naldi A, Montuschi A: Dementia and cognitive impairment in amyotrophic lateral sclerosis: a review. Neurol Sci 2010;32:9-16.

$\checkmark 97$ Lillo P, Garcin B, Hornberger M, Bak TH, Hodges JR: Neurobehavioral features in frontotemporal dementia with amyotrophic lateral sclerosis. Arch Neurol 2010;67:826830.

98 Lomen-Hoerth C: Characterization of amyotrophic lateral sclerosis and frontotemporal dementia. Dement Geriatr Cogn Disord 2004; 17:337-341.

99 Sabbagh MN, Adler CH, Lahti TJ, Connor DJ, Vedders L, Peterson LK, Caviness JN, Shill HA, Sue LI, Ziabreva I, Perry E, Ballard CG, Aarsland D, Walker DG, Beach TG: Parkinson disease with dementia: comparing patients with and without Alzheimer pathology. Alzheimer Dis Assoc Disord 2009;23: 295-297. 